\title{
Study on Axial Compressive Capacity of FRP-Confined Concrete-Filled Steel Tubes and Its Comparisons with Other Composite Structural Systems
}

\author{
Jun Deng, Yifeng Zheng, Yi Wang, Tonghua Liu, and Hui Li \\ School of Civil and Transportation Engineering, Guangdong University of Technology, Guangzhou 510006, China \\ Correspondence should be addressed to Jun Deng; jdeng@gdut.edu.cn
}

Received 14 September 2016; Revised 15 January 2017; Accepted 23 January 2017; Published 16 February 2017

Academic Editor: Atsushi Sudo

Copyright (C) 2017 Jun Deng et al. This is an open access article distributed under the Creative Commons Attribution License, which permits unrestricted use, distribution, and reproduction in any medium, provided the original work is properly cited.

\begin{abstract}
Concrete-filled steel tubular (CFST) columns have been widely used for constructions in recent decades because of their high axial strength. In CFSTs, however, steel tubes are susceptible to degradation due to corrosion, which results in the decrease of axial strength of CFSTs. To further improve the axial strength of CFST columns, carbon fiber reinforced polymer (CFRP) sheets and basalt fiber reinforced polymer (BFRP) sheets are applied to warp the CFSTs. This paper presents an experimental study on the axial compressive capacity of CFRP-confined CFSTs and BFRP-confined CFSTs, which verified the analytical model with considering the effect of concrete self-stressing. CFSTs wrapped with FRP exhibited a higher ductile behavior. Wrapping with CFRP and BFRP improves the axial compressive capacity of CFSTs by $61.4 \%$ and $17.7 \%$, respectively. Compared with the previous composite structural systems of concrete-filled FRP tubes (CFFTs) and double-skin tubular columns (DSTCs), FRP-confined CFSTs were convenient in reinforcing existing structures because of softness of the FRP sheets. Moreover, axial compressive capacity of CFSTs wrapped with CFRP sheets was higher than CFFTs and DSTCs, while the compressive strength of DSTCs was higher than the retrofitted CFSTs.
\end{abstract}

\section{Introduction}

In a conventional concrete-filled steel tubular (CFST) column system, concrete was filled in steel tubes, which typically continued throughout several stories or the full-height of a building $[1,2]$. After decades of development, CFST columns have been widely used in many buildings.

In CFSTs, however, steel tubes are susceptible to degradation due to corrosion, which results in the reducing of axial strength of CFSTs. To overcome the disadvantages, Xiao [3] proposed the FRP strengthened CFST (FCFST) columns. Both the inward and the outward buckling deformations of the steel tube in the strengthened CFSTs were constrained, thereby substantially enhancing the ductility and strength of the column. Thereafter, many studies were conducted by Xiao et al. [4-6] and other researchers [5, 7-11] on the effectiveness of FRP wrapping in improving the structural behavior of CFST columns. Teng et al. [12] developed a stress-strain model for confined concrete in FCFSTs.
Xue et al. [13] have found that shrinkage of the filled concrete can cause separation between steel tube and concrete, and Ghafari et al. [14] have found that shrinkage can reduce the durability of the structures. Expansive cements, which can increase the volume of concrete due to chemical reactions, can reduce the shrinkage of concrete. Therefore, the selfstressing concrete-filled steel tubes (SSCFSTs) were proposed as they have higher axial strength than CFSTs. A number of experimental studies $[15,16]$ on SSCFST have been conducted to understand its mechanical performance, and design theory [17] was proposed accordingly. Some models have been developed to predict the load capacity of the FCFST columns $[18,19]$; however, the effect of the expansion of the concrete was not considered.

In addition, CFST is not the only system of concretefilled tubular columns. Ozbakkaloglu et al. [20-22] conducted studies on the axial compressive behavior of concretefilled FRP tubes (CFFTs) and double-skin tubular columns (DSTCs). CFSTs were made of steel tubes, while CFFTs were 

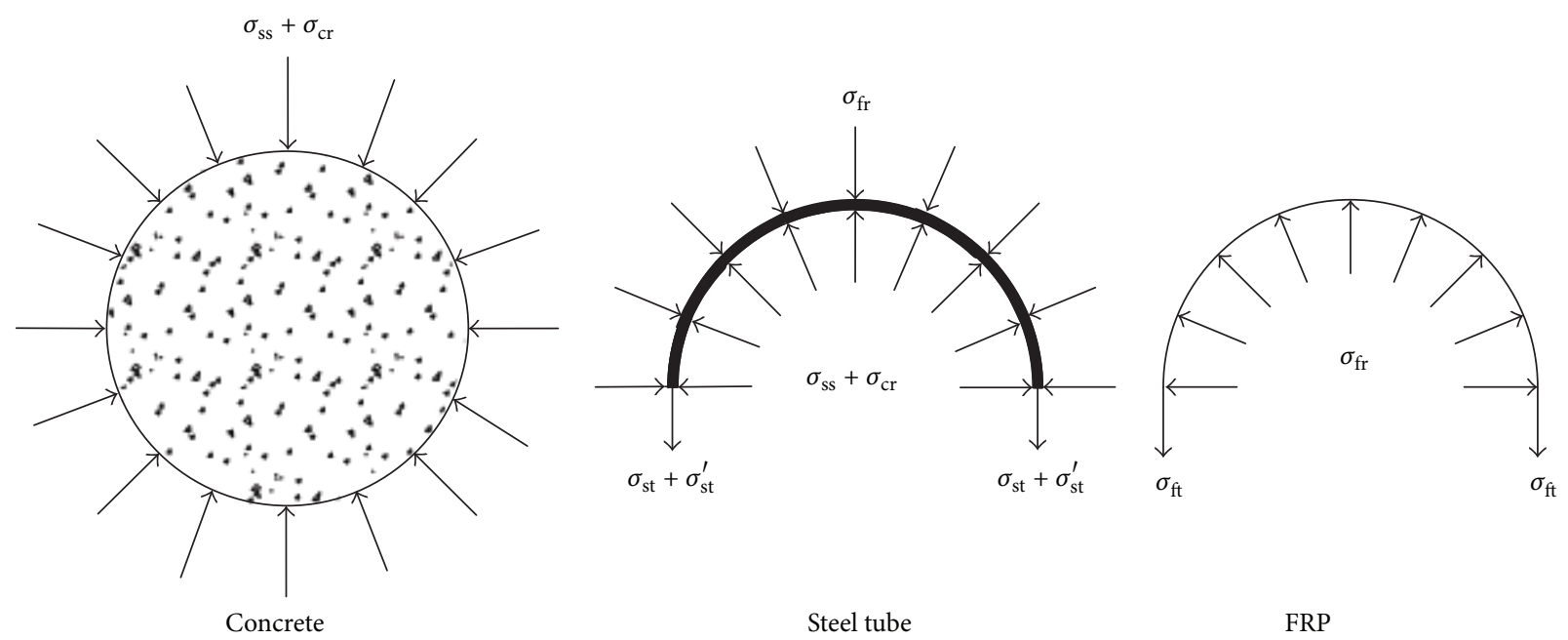

Steel tube

FRP

FIgURE 1: Stress distribution in SSCFST.

made of FRP tubes. DSTCs were made of both steel tubes and FRP tubes, including hollow core (DSTC-H) and corefilled (DSTC-F). Since the characteristics and application limitations of each system are still not clear, the comparisons of these four systems are needed.

This paper gives a theoretical model for obtaining the axial compressive capacity of FCFSTs, in which the effect of self-stressing was considered. Besides, experimental study was also conducted to investigate the behavior of CFSTs wrapped with CFRP sheets (CCFSTs) and BFRP sheets (BCFSTs) subjected to axial compression. Finally, our test results were compared with existing test results of CFFT, DSTC-H, and DSTC-F.

\section{Analytical Study}

2.1. Basic Assumptions. The following assumptions are made in this analytical study:

(1) The interfaces between the concrete and the steel tube, the steel tube and the FRP sheet are constrained.

(2) The radial stress in the steel tube is ignored and the steel tube is under biaxial stress.

(3) The FRP material is linear elastic.

(4) Only the hoop stress in the FRP sheet is considered; that is, the stress along the fiber direction is considered and the radial stress and the longitudinal stress are ignored.

2.2. Axial Compressive Capacity. Since the concrete in the steel tube is under triaxial compression, the axial compressive strength of concrete $\sigma_{\mathrm{cl}}$ which considered both the selfstressing and axial compression can be expressed as [23]

$$
\sigma_{\mathrm{cl}}=f_{\mathrm{ck}}+k\left(\sigma_{\mathrm{cr}}+\sigma_{\mathrm{ss}}\right) \text {, }
$$

where $f_{\mathrm{ck}}$ is the standard compressive strength of the concrete, $\sigma_{\mathrm{r}}$ the lateral pressure of the concrete, $\sigma_{\mathrm{cr}}$ the lateral stress of the concrete core caused by axial compression, $\sigma_{\mathrm{ss}}$ the initial lateral stress caused by expansion of the self-stressing concrete, and $k$ the lateral stress coefficient. $k$ is normally between 3 and 5 in accordance with the experimental results [23] and assumed to be 4 in this study.

The critical state of the steel tube is analyzed using the maximum shear stress theory, known as Tresca yield criterion. It can be expressed as

$$
\sigma_{\mathrm{st}}-\sigma_{\mathrm{sl}}+\sigma_{\mathrm{st}}^{\prime}=f_{\mathrm{y}}
$$

where $\sigma_{\text {st }}$ and $\sigma_{\text {sl }}$ are the hoop tensile stress and axial compressive stress of the steel tube, respectively. $\sigma_{\text {st }}^{\prime}$ is the hoop tensile stress of steel tube that caused by self-stressing and $f_{\mathrm{y}}$ is the yield strength of the steel tube.

According to the basic assumption (1) and the stressstrain relationships of FRP and steel tube, the hoop stress of the FRP $\sigma_{\mathrm{ft}}$ can be expressed as

$$
\sigma_{\mathrm{ft}}=\frac{E_{\mathrm{f}}}{E_{\mathrm{s}}}\left[\left(1-\mu_{\mathrm{s}}\right) \sigma_{\mathrm{st}}-\mu_{\mathrm{s}} \sigma_{\mathrm{st}}^{\prime}+\mu_{\mathrm{s}} f_{\mathrm{y}}\right],
$$

where $E_{\mathrm{s}}, \mu_{\mathrm{s}}$, and $E_{\mathrm{f}}$ are Poisson's ratio and Young's modulus of the steel tube and the Young's modulus of the FRP sheet, respectively.

Figure 1 shows the stress distribution in SSCFST under axial compression. According to the stress balances in Figure $1, \sigma_{\mathrm{cr}}$ and $\sigma_{\mathrm{ss}}$ can be expressed as

$$
\begin{aligned}
\sigma_{\mathrm{cr}} & =\sigma_{\mathrm{ft}} \frac{A_{\mathrm{f}}}{2 A_{\mathrm{c}}}+\sigma_{\mathrm{st}} \frac{A_{\mathrm{s}}}{2 A_{\mathrm{c}}}, \\
\sigma_{\mathrm{ss}} & =\frac{A_{\mathrm{s}}}{2 A_{\mathrm{c}}} \sigma_{\mathrm{st}}^{\prime},
\end{aligned}
$$

where $A_{\mathrm{c}}, A_{\mathrm{s}}$, and $A_{\mathrm{f}}$ are the cross-sectional areas of the concrete, the steel tube, and the FRP, respectively.

The axial compressive capacity of the FRP-SSCFST can be described as

$$
N_{\mathrm{u}}=A_{\mathrm{c}} \sigma_{\mathrm{cl}}+A_{\mathrm{s}} \sigma_{\mathrm{sl}}
$$




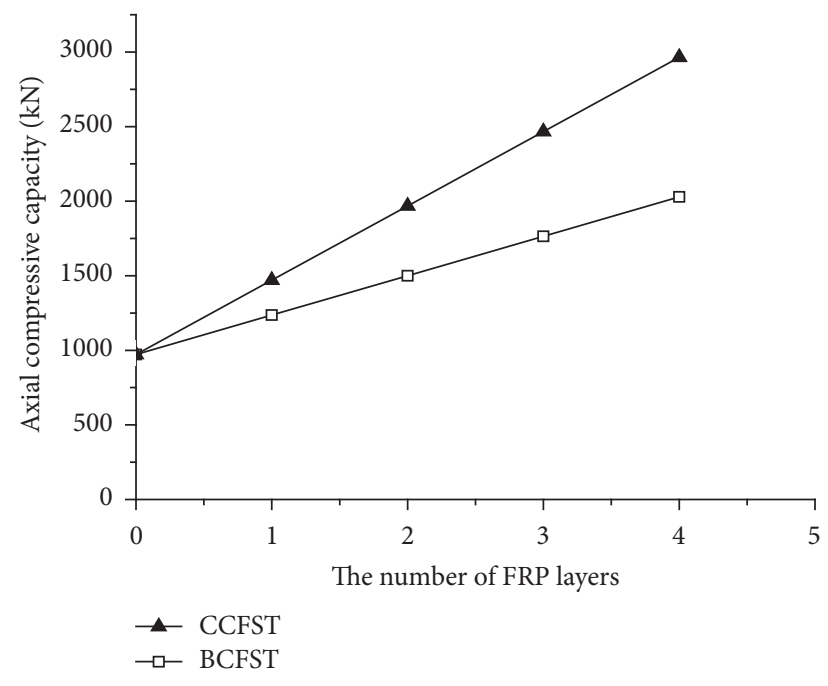

FIGURE 2: Axial compressive capacity with the number of FRP layers.

This study considers the following failure modes of the FRP-SSCFST: steel tube bucking and FRP sheet rupturing.

(1) When the failure mode is steel tube bucking, the hoop tensile stress of the steel tube $\sigma_{\text {st }}$ is the yield stress $f_{\mathrm{y}}$. Substituting (1), (2), (3), (4), and (5) into (6) gives axial compressive capacity as

$$
\begin{aligned}
& N_{\mathrm{u}} \\
& \quad=A_{\mathrm{c}} f_{\mathrm{ck}}\left[1+2 \xi_{\mathrm{s}}+2 \frac{E_{\mathrm{f}}}{E_{\mathrm{s}}} \xi_{\mathrm{f}}+\left(6-\frac{4 E_{\mathrm{f}} A_{\mathrm{f}}}{E_{\mathrm{s}} A_{\mathrm{s}}} \mu_{\mathrm{s}}\right) \frac{\sigma_{\mathrm{ss}}}{f_{\mathrm{ck}}}\right]
\end{aligned}
$$

where

$$
\begin{gathered}
\xi_{\mathrm{s}}=\frac{A_{\mathrm{s}} f_{\mathrm{y}}}{A_{\mathrm{c}} f_{\mathrm{ck}}}, \\
\xi_{\mathrm{f}}=\frac{A_{\mathrm{f}} f_{\mathrm{f}}}{A_{\mathrm{c}} f_{\mathrm{ck}}} .
\end{gathered}
$$

$\xi_{\mathrm{s}}$ and $\xi_{\mathrm{f}}$ are defined as the coefficients of the constraint effect caused by the steel tube and the FRP sheet, respectively.

(2) When the failure mode is FRP sheet rupturing, the hoop tensile stress of the steel tube $\sigma_{\mathrm{st}}$ is the yield stress $f_{\mathrm{y}}$ and the hoop tensile stress of the FRP $\sigma_{\mathrm{ft}}$ is the ultimate stress $f_{\mathrm{f}}$. Substituting (1), (2), and (4) into (6) gives axial compressive capacity as

$$
N_{\mathrm{u}}=A_{\mathrm{c}} f_{\mathrm{ck}}\left(1+2 \xi_{\mathrm{s}}+2 \xi_{\mathrm{f}}+6 \frac{\sigma_{\mathrm{ss}}}{f_{\mathrm{ck}}}\right) .
$$

2.3. Parametric Analysis. Parametric analysis was performed to investigate the effects of the number of FRP layers and the self-stressing on the axial compressive capacity. The less one between the results calculated by (7) and (9) was the axial compressive capacity of the retrofitted CFSTs.

Figure 2 plots the axial compressive capacity versus the number of layers of FRP sheets. It shows that the axial compressive capacity increased with the number of FRP

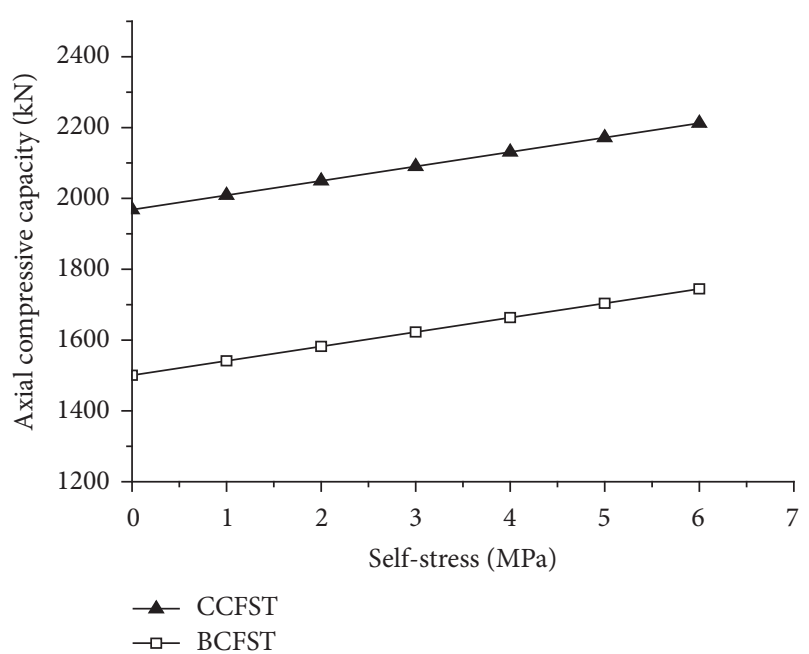

FIGURE 3: Axial compressive capacity with the self-stress.

TABLE 1: Material parameters of CFST.

\begin{tabular}{lccc}
\hline Materials & $\begin{array}{c}\text { Yield strength } \\
(\mathrm{MPa})\end{array}$ & $\begin{array}{c}\text { 28-day compressive } \\
\text { strength } \\
(\mathrm{MPa})\end{array}$ & $\begin{array}{c}\text { Young's } \\
\text { modulus } \\
(\mathrm{GPa})\end{array}$ \\
\hline steel & 275 & - & 201 \\
concrete & - & 31.2 & $3.35 \times 10^{-5}$ \\
\hline
\end{tabular}

Note. The mix proportions of the concrete were $190: 400: 786: 1065: 8$ (water: cement: sand : aggregate : water reducer).

TABLE 2: Material parameters of FRP.

\begin{tabular}{lccc}
\hline FRP types & $\begin{array}{c}\text { Slice thickness } \\
(\mathrm{mm})\end{array}$ & $\begin{array}{c}\text { Tensile strength } \\
(\mathrm{MPa})\end{array}$ & $\begin{array}{c}\text { Young's modulus } \\
(\mathrm{GPa})\end{array}$ \\
\hline CFRP & 0.167 & 2878 & 244 \\
BFRP & 0.167 & 1526 & 71 \\
\hline
\end{tabular}

layers and the axial strength of CCFSTs is higher than that of BCFSTs. This is because the lateral restraint can be effectively enhanced with the thickness and ultimate tensile strength of FRP, thereby increasing the axial compressive capacity.

Figure 3 plots the axial compressive capacity versus selfstressing level of the filled concrete. It shows that the axial compressive capacity increased with the self-stress. This is because that the lateral restraint increased with the self-stress, thereby increasing the axial compressive capacity.

\section{Experimental Study}

In total, 11 specimens were prepared, including 3 CFSTs, 4 CCFSTs, and 4 BCFSTs.

Table 1 shows the parameters of steel and concrete of CFSTs. Table 2 shows the parameters of CFRP and BFRP.

After cutting the steel tubes into the desired dimensions, specimens were cast. Then two layers of FRP were wrapped in the hoop direction covering the whole steel tube after 28 days curing.

The tests were carried out in a servohydraulic test machine with a maximum capacity of $10000 \mathrm{kN}$. The load was 


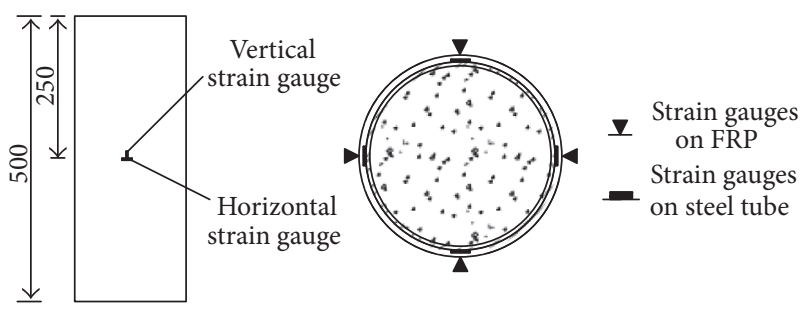

FIGURE 4: Strain gauges arrangement for specimens.

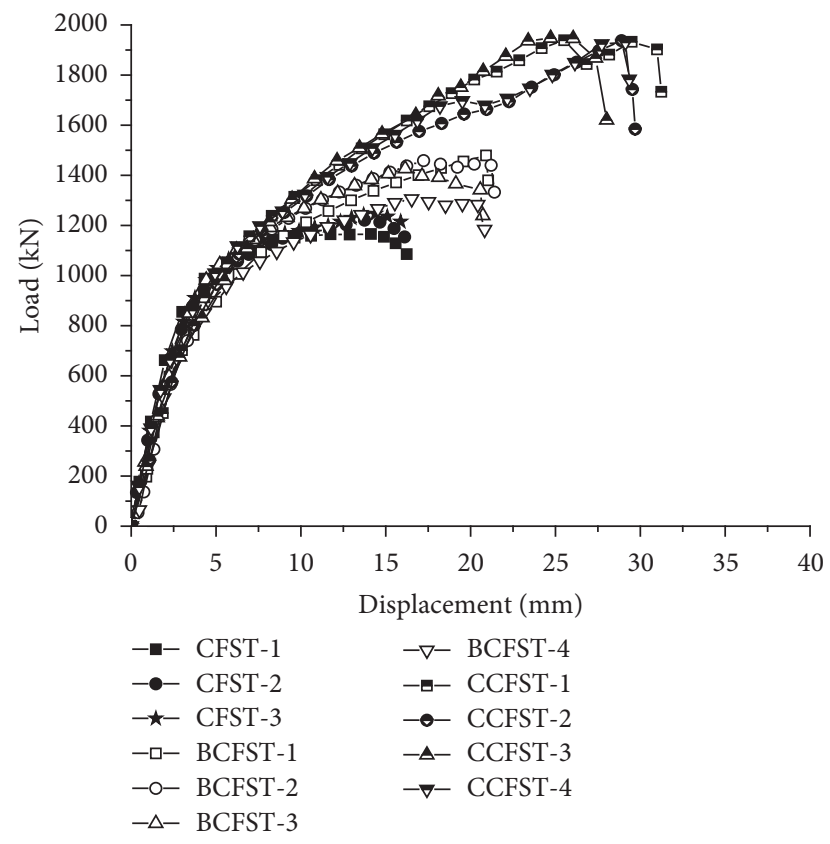

FIGURE 5: Load-displacement curves.

applied at a constant rate of $0.5 \mathrm{kN} / \mathrm{s}$ during the elastic stage and at a constant rate of $0.25 \mathrm{~mm} / \mathrm{min}$ during the plastic stage until the specimens reached its ultimate axial compressive capacity. Four pairs of $3 \mathrm{~mm}$ long strain gauges were mounted on both the exterior of the steel tubes and FRP at the midheight of the specimens to capture the longitudinal and hoop strains. All data was automatically recorded by a data logging system (TDS-530). The strain gauges' arrangement was shown in Figure 4.

\section{Experimental Results and Discussions}

4.1. Strength and Stiffness of the Specimens. The load versus displacement of the specimens is shown in Figure 5. All specimens have the same loading steps, which can be classified into four stages: elastic stage, elastic-plastic stage, plastic stage, and failure stage. During the elastic stage, the load is apportioned according to the proportion of stiffness between FRP, steel, and concrete. Therefore, after calculation, it can be seen that the load steel suffered is more than $80 \%$ of the whole load, which is much greater than FRP and concrete. The stiffness of steel plays a leading role in this stage, which results in the stiffness of FCFST specimens closed to that of the CFST

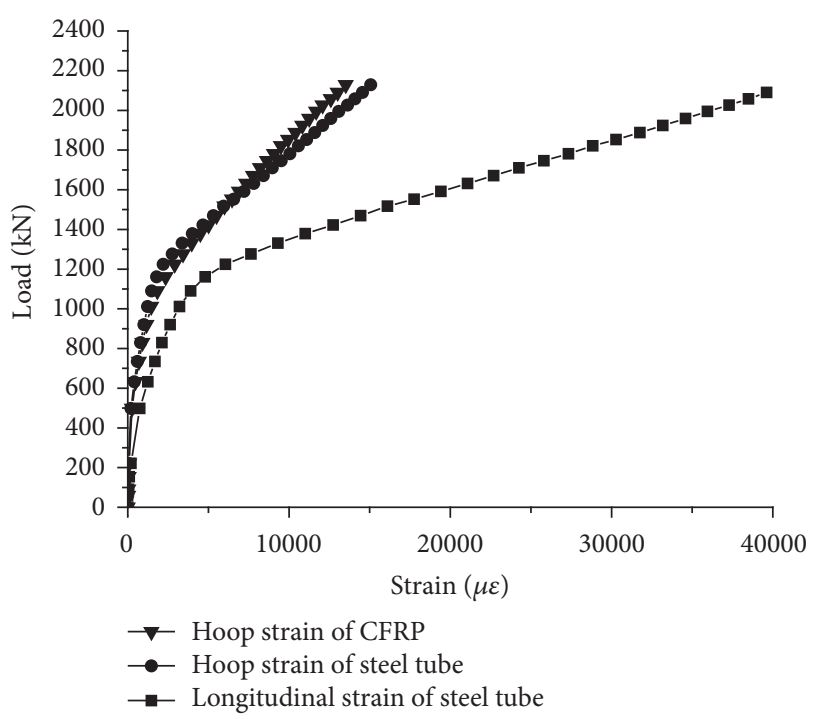

FIgURE 6: Load-strain curves of CCFST-3.

specimens. During the elastic-plastic stage, the stiffness of the strengthened specimens, especially the CCFST specimens, was significantly higher than the CFST specimens. Because outward buckling deformation of the steel tube was constrained by FRP wrapping, the CFRP has more effective confinement than BFRP because of its higher Young's modulus.

The average axial compressive capacity of CFSTs, CCFSTs, and BCFSTs was $1207 \mathrm{kN}, 1949 \mathrm{kN}$ and $1421 \mathrm{kN}$, respectively. The CFRP and BFRP strengthening enhanced the axial compressive capacity of CFSTs by $61.4 \%$ and $17.7 \%$, respectively. The average ultimate displacement of CFSTs, CCFSTs, and BCFSTs was $16 \mathrm{~mm}, 30 \mathrm{~mm}$, and $20 \mathrm{~mm}$, respectively. Besides, CFRP and BFRP strengthening enhanced the ductility by $87.5 \%$ and $25 \%$, respectively. It indicates that the strength and ductility of the CFSTs can be significantly improved by FRP wrapping, especially CFRP wrapping.

4.2. Strains of the Specimens. The hoop strain of CFRP and hoop and longitudinal strain of steel tube recorded during the tests of CCFST-3 and BCFST-1 are shown in Figures 6 and 7 , respectively. It can be seen that the hoop strains of both CFRP and steel tube were very small during the elastic stage. This is because that the steel tube and the concrete carried on the axial load and the confinement of the steel tube and FRP sheets was not pronounced. The longitudinal strains of the steel tubes developed as elastic-perfectly plastic body. Comparing Figures 6 and 7, the ultimate longitudinal strain of the steel tubes in the CCFST is larger than that in the BCFST, which shows that the confinement of CFRP wrapping is more effective. The load-strain curves of the FRP developed consistently with those of the steel tubes, which indicates that the FRP wraps and steel tube can work together well. Similar results were obtained from the other strengthened specimens.

4.3. Failure Modes. All specimens were loaded to failure to understand the effect of the FRP on the axial strength of CFSTs. The failure modes of typical specimens were shown 


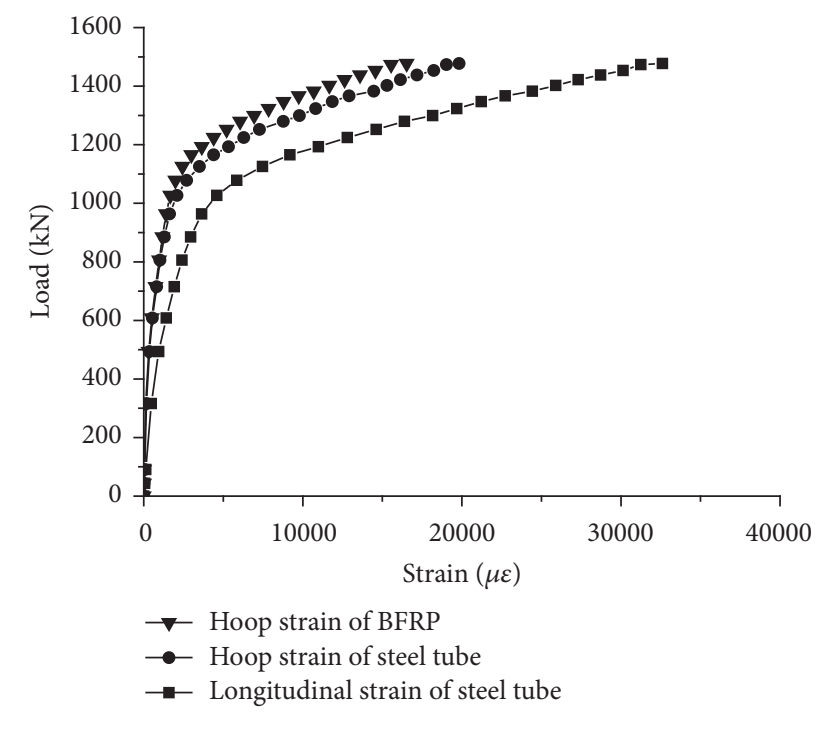

FIgURE 7: Load-strain curves of BCFST-1.

TABle 3: Comparisons of axial compressive capacity from experiment and analytical results.

\begin{tabular}{|c|c|c|c|}
\hline \multirow{2}{*}{ Specimens } & \multicolumn{2}{|c|}{ Axial compressive capacity $(\mathrm{kN})$} & \multirow{2}{*}{$\begin{array}{l}\text { Deviations } \\
(\%)\end{array}$} \\
\hline & $\begin{array}{c}\text { Average experimental } \\
\text { results }\end{array}$ & Analytical results & \\
\hline CFSTs & 1207.3 & 1198 & -4.01 \\
\hline CCFSTs & 1948.8 & 2037 & 4.53 \\
\hline BCFSTs & 1420.5 & 1247 & -12.21 \\
\hline
\end{tabular}

in Figure 8. As shown in Figure 8(a), the outward bucking of CFSTs was observed in the middle of the steel tube at failure load. In the case of FRP strengthened specimens, snapping sound of fiber was observed after steel tube yielded. The reason could be that FRP wrapping provided significant restraint against the lateral deformations of concrete core and steel tube and the FRP was subjected to tension in the hoop direction. When the FRP reached its ultimate strain, rupture of FRP occurred followed by the outward bucking of steel tube in the middle of the specimens, as shown in Figures 8(b) and $8(\mathrm{c})$.

4.4. Validating Analytical Analysis. The axial compressive capacity of the specimens obtained from tests was compared to the corresponding analytical results calculated by (7) or (9), as presented in Table 3 . The agreement between the experimental and analytical results of CFSTs was reached. The deviations of experimental and analytical results of CCFSTs and BCFSTs are $4.53 \%$ and $-12.21 \%$, respectively, which is considered acceptable.

\section{Comparisons of CFST, CFFT, DSTC-H, and DSTC-F}

Over the past five years, significant numbers of studies have been reported on the composite columns such as CFFT, DSTC, and FCFST, in which Ozbakkaloglu et al. [20-22]

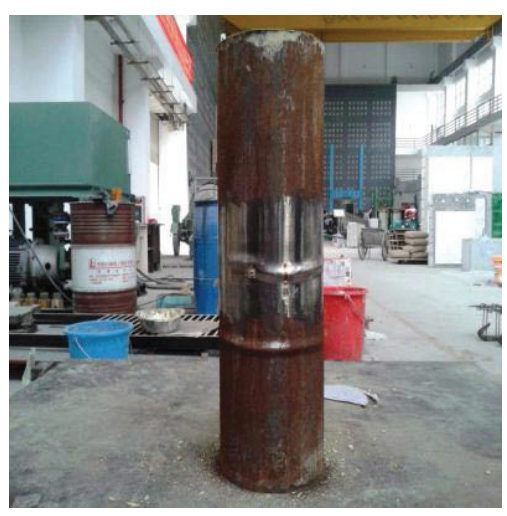

(a) CFST

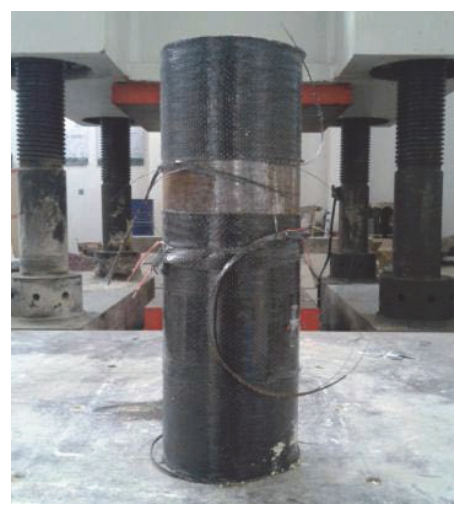

(b) CCFST

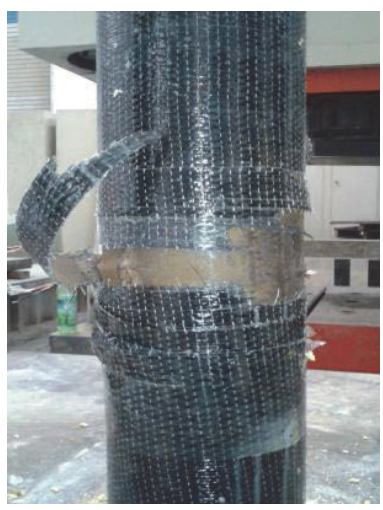

(c) BCFST

FIGURE 8: Failure modes of specimens.

conducted studies on axial compressive behavior of CFFT, DSTC-H, and DSTC-F made of normal-strength and highstrength concrete, making great contribution to the new composite structure systems. To date, there are few literatures on the contrasted analysis of axial compressive strength and capacity of the different composite columns. The schematics of the four types of columns in literatures $[20,21]$ and this study were shown in Figure 9.

Table 4 shows the axial compressive capacity $\left(N_{\mathrm{u}}\right)$ and axial compressive strength $\left(f_{\mathrm{cc}}\right)$ obtained from the experimental results of the four types of columns made of CFRP. It demonstrates that the axial compressive capacity $\left(N_{\mathrm{u}}\right)$ of 


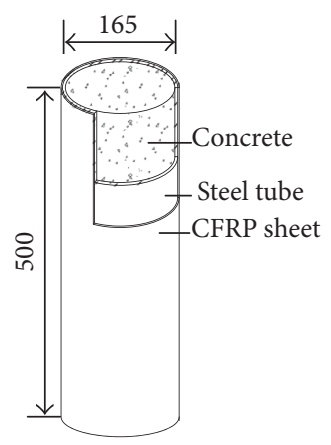

CCFST
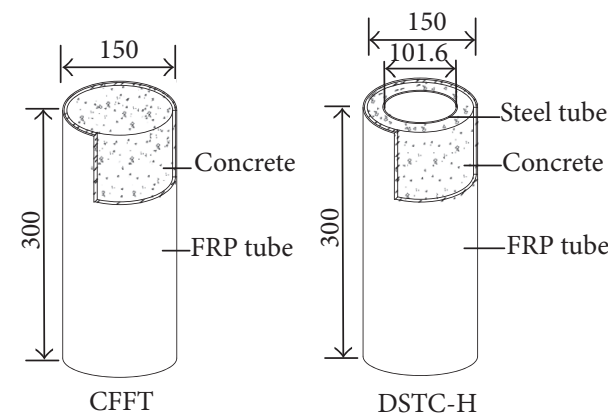

DSTC-H

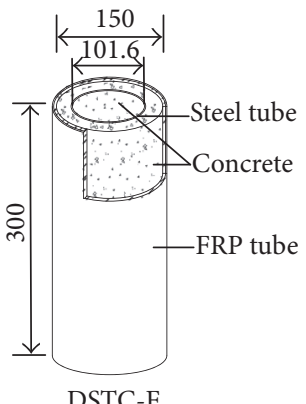

DSTC-F

FIGURE 9: The schematics of four columns.

TABLE 4: Comparisons of CCFST, CFFT, DSTC-H, and DSTC-F.

\begin{tabular}{lcccccccc}
\hline Type & Specimen & $t_{\mathrm{f}}(\mathrm{mm})$ & $t_{\mathrm{s}}(\mathrm{mm})$ & $f_{\mathrm{c}}(\mathrm{MPa})$ & $f_{\mathrm{y}}(\mathrm{MPa})$ & $f_{\mathrm{f}}(\mathrm{MPa})$ & $N_{\mathrm{u}}(\mathrm{kN})$ & $f_{\mathrm{cc}}(\mathrm{MPa})$ \\
\hline CCFST & average & 0.334 & 2.0 & 31.2 & 275 & 2878 & 1948.8 \\
CFFT [20] & N-150C2L-2 & 0.234 & - & 34.6 & - & 3626 & 1104.5 & 61.2 \\
DSTC-H [21] & DSTC-2 & 0.234 & 3.2 & 37.0 & 302 & 3626 & 955.0 \\
DSTC-F [21] & DSTC-4 & 0.234 & 3.2 & 36.7 & 302 & 3626 & 1322.0 & 74.9 \\
\hline
\end{tabular}

Note. $f_{\mathrm{c}}=$ the 28 -day compressive strength of concrete; $t_{\mathrm{f}}=$ the total nominal thickness of CFRP; $t_{\mathrm{s}}=$ the thickness of steel tube; CFRP tubes of CFFT, DSTC$\mathrm{H}$, and DSTC-F were made of two layers of CFRP (nominal thickness is $0.117 \mathrm{~mm} / \mathrm{ply}$ ), while CCFSTs were wrapped with two layers of CFRP sheets (nominal thickness is $0.167 \mathrm{~mm} / \mathrm{ply}$ ).

CCFSTs is higher than those of CFFT, DSTC-H, and DSTCF. However, the cross-sectional area of CCFSTs is the largest in the four types of columns. The axial compressive strength $\left(f_{\mathrm{cc}}\right)$ of DSTC-H is greater than CCFSTs and CFFT. Overall, the four types of columns have their own advantages: (a) CFFTs do not need steel and DSTC-H can cost less concrete; (b) DSTC-H is lighter than CCFST and CFFT; (c) CFFT, DSTC-H, and DSTC-F are used as new structures, while CCFST is generally applied to reinforce existing structures; (d) as the novel structures, CFFT and DSTC are applied by well-shaped columns in present; (e) CCFST is conveniently utilized in the structures of the steel tube columns reinforced in active service, which benefits from softness of the FRP sheets.

\section{Conclusions}

This paper investigated the axial compressive capacity and strength of FCFSTs. Theoretical study was presented to predict the nominal axial compressive strength of FCFSTs, in which the effect of self-stressing concrete was considered. In addition, the experimental study was also conducted to verify the model and investigate the behavior of CCFSTs and BCFSTs subjected to axial compression. As discussed, the following conclusions can be reached.

(1) The axial compressive capacity of the CFSTs wrapped with CFRP and BFRP was improved by $61.4 \%$ and $17.7 \%$, respectively. Besides, the ductility of the CFSTs was improved as well.

(2) The good agreement between the experimental axial strength and the analytical results confirmed the validity of the theoretical model.
(3) CCFST can be conveniently and effectively utilized in the existing structure strengthening, while CFFT, DSTC$\mathrm{H}$, and DSTC-F are applied by well-shaped column as novel structures. Among the four types of columns, DSTC-H has the highest compressive strength.

\section{Competing Interests}

The authors declare that there is no conflict of interests regarding the publication of this paper.

\section{Acknowledgments}

This work is supported by the National Natural Science Foundation of China through Grant 51278131, Program for New Century Excellent Talents in University through Grant NCET-13-0739, and Fok Ying Tong Education Foundation through Grant 131073.

\section{References}

[1] W. P. Moore and N. K. Gosain, "Mixed systems, past practices, recent experience and future direction," in Proceedings of the Composite and Mixed Construction, ASCE, pp. 138-149, 1985.

[2] I. M. Viest, J. P. Colaco, R. W. Furlong, L. G. Griffis, R. T. Leon, and L. A. Wyllie, Composite Construction: Design for Buildings, John Wiley \& Sons, New York, NY, USA, 1997.

[3] Y. Xiao, "Applications of FRP composites in concrete columns," Advances in Structural Engineering, vol. 7, no. 4, pp. 335-343, 2004. 
[4] X. Y. Mao and Y. Xiao, "Seismic behavior of confined square CFT columns," Engineering Structures, vol. 28, no. 10, pp. 13781386, 2006.

[5] J. H. Shan, R. Chen, W. X. Zhang, Y. Xiao, W. J. Yi, and F. Y. $\mathrm{Lu}$, "Behavior of concrete filled tubes and confined concrete filled tubes under high speed impact," Advances in Structural Engineering, vol. 10, no. 2, pp. 209-218, 2007.

[6] Y. Xiao, W. He, and K.-K. Choi, "Confined concrete-filled tubular columns," Journal of Structural Engineering, vol. 131, no. 3, pp. 488-497, 2005.

[7] W. Gu, C. W. Guan, Y. H. Zhao, and H. Cao, "Experimental study on concentrically compressed circular concrete filled CFRP-steel composite tubular short columns," Journal of Shenyang Archit Engineering University (Natural Science), vol. 20, no. 2, pp. 118-120, 2004.

[8] Z. Tao, L.-H. Han, and J.-P. Zhuang, "Axial loading behavior of CFRP strengthened concrete-filled steel tubular stub columns," Advances in Structural Engineering, vol. 10, no. 1, pp. 37-46, 2007.

[9] Z.-B. Wang, Z. Tao, and L.-H. Han, "Performance of CFRPstrenghtened concrete filled steel tubes under axial compression," in Proceedings of the 10th International Symposium on Structural Engineering for Young Experts (ISSEYE '08), pp. 689694, Changsha, China, October 2008.

[10] L. Liu and Y. Y. Lu, "Axial bearing capacity of short FRP confined concrete-filled steel tubular columns," Journal Wuhan University of Technology-Materials Science Edition, vol. 25, no. 3, pp. 454-458, 2010.

[11] J. W. Park, Y. K. Hong, and S. M. Choi, "Behaviors of concrete filled square steel tubes confined by carbon fiber sheets (CFS) under compression and cyclic loads," Steel and Composite Structures, vol. 10, no. 2, pp. 187-205, 2010.

[12] J. G. Teng, Y. M. Hu, and T. Yu, "Stress-strain model for concrete in FRP-confined steel tubular columns," Engineering Structures, vol. 49, pp. 156-167, 2013.

[13] J.-Q. Xue, B. Briseghella, and B.-C. Chen, "Effects of debonding on circular CFST stub columns," Journal of Constructional Steel Research, vol. 69, no. 1, pp. 64-76, 2012.

[14] E. Ghafari, S. A. Ghahari, H. Costa, E. Júlio, A. Portugal, and L. Durães, "Effect of supplementary cementitious materials on autogenous shrinkage of ultra-high performance concrete," Construction and Building Materials, vol. 127, pp. 43-48, 2016.

[15] C. Maltese, C. Pistolesi, A. Lolli, A. Bravo, T. Cerulli, and D. Salvioni, "Combined effect of expansive and shrinkage reducing admixtures to obtain stable and durable mortars," Cement and Concrete Research, vol. 35, no. 12, pp. 2244-2251, 2005.

[16] L. Xu, Research on the design theory for self-stressing and selfcompacting concrete filled steel tube column under axial load [Ph.D. thesis], Dalian University of Technology, Dalian, China, 2005.

[17] Z. Q. Shang, Research on mechanical behavior of self-stressing and self-compacting concrete filled steel tube columns [Ph.D. thesis], Dalian University of Technology, Dalian, China, 2007.

[18] Y. Lu, N. Li, and S. Li, "Behavior of FRP-confined concrete-filled steel tube columns," Polymers, vol. 6, no. 5, pp. 1333-1349, 2014.

[19] Z.-B. Wang, Q. Yu, and Z. Tao, "Behaviour of CFRP externallyreinforced circular CFST members under combined tension and bending," Journal of Constructional Steel Research, vol. 106, pp. 122-137, 2015.

[20] T. Ozbakkaloglu and T. Vincent, "Axial compressive behavior of circular high-strength concrete-filled FRP tubes," Journal of Composites for Construction, vol. 18, no. 2, Article ID 04013037, 2014.
[21] T. Ozbakkaloglu and B. L. Fanggi, "Axial compressive behavior of FRP-concrete-steel double-skin tubular columns made of normal- and high-strength concrete," Journal of Composites for Construction, vol. 18, no. 1, Article ID 04013027, 2014.

[22] B. A. L. Fanggi and T. Ozbakkaloglu, "Behavior of hollow and concrete-filled FRP-HSC and FRP-HSC-steel composite columns subjected to concentric compression," Advances in Structural Engineering, vol. 18, no. 5, pp. 715-738, 2015.

[23] S. H. Cai, Modern Concrete Filled Steel Tubular Structures, Communications Press, Beijing, China, 2003. 

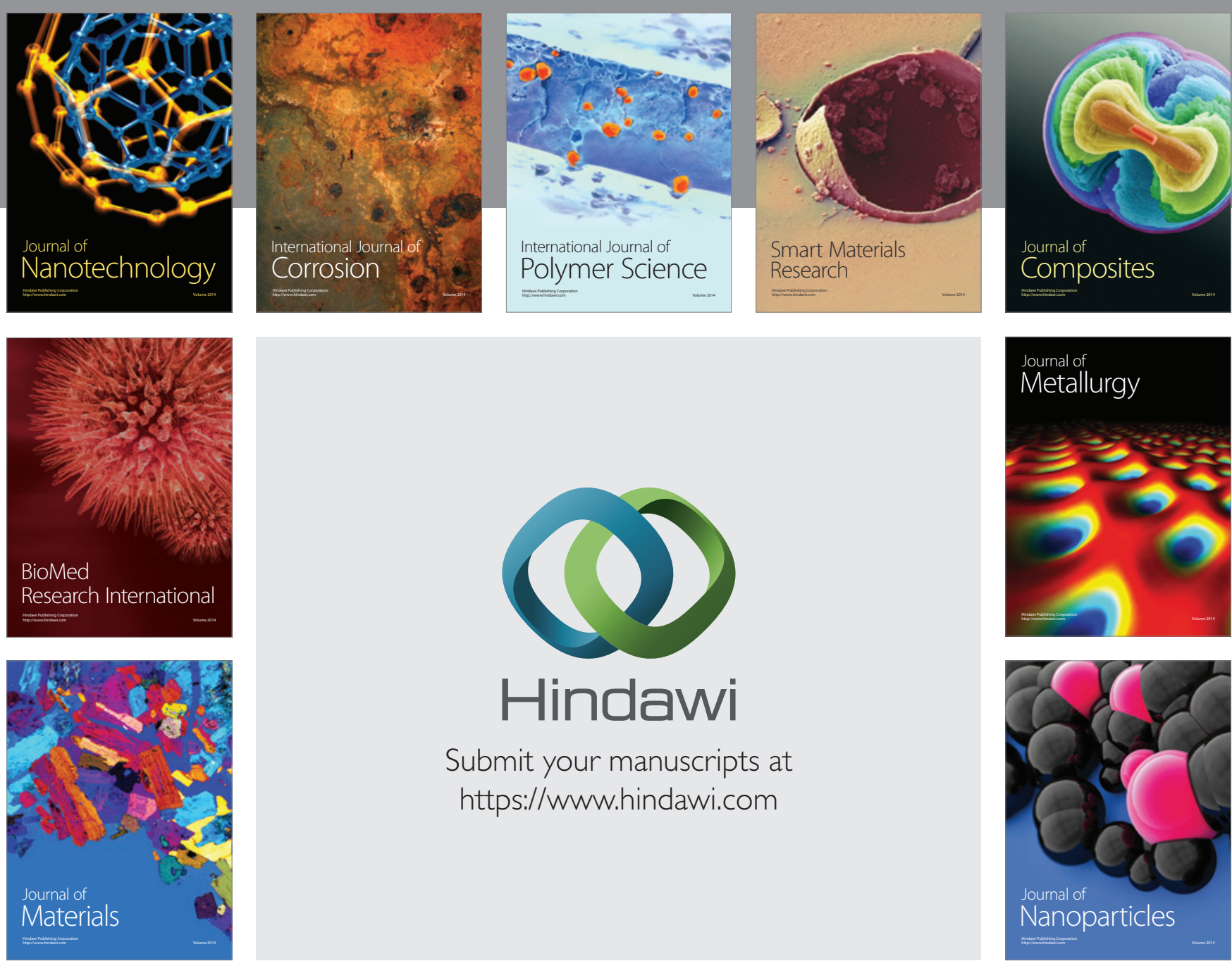

\section{Hindawi}

Submit your manuscripts at

https://www.hindawi.com

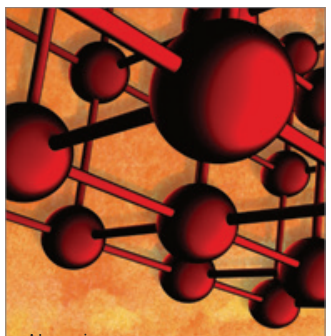

Materials Science and Engineering
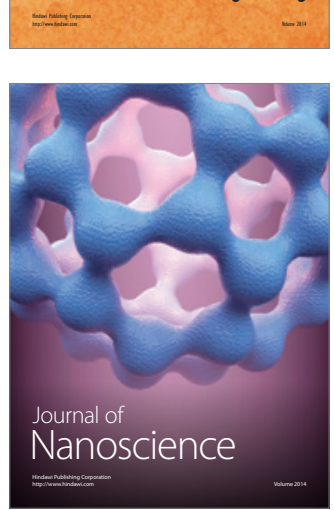
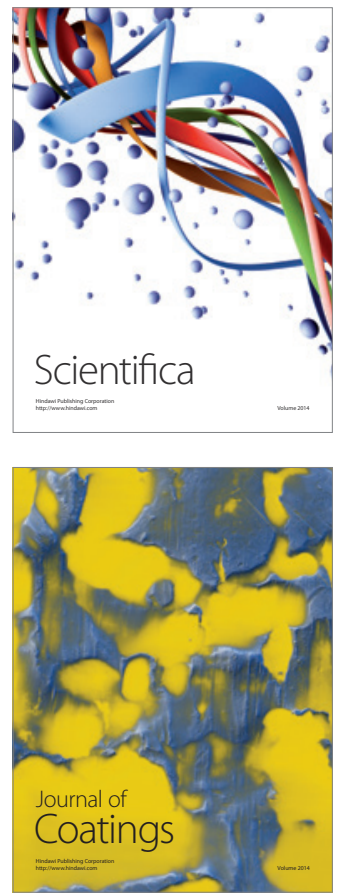
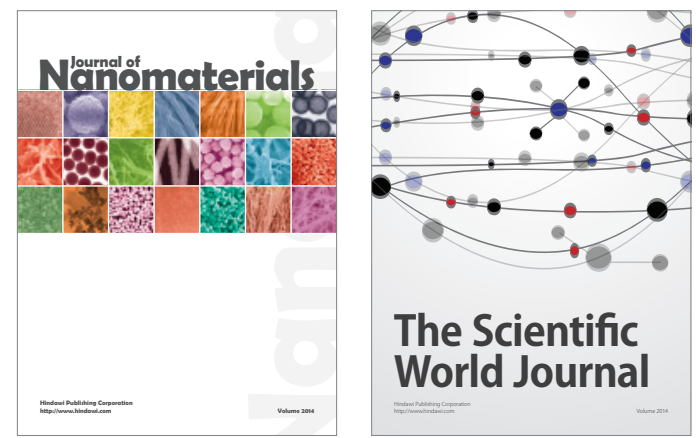

The Scientific World Journal
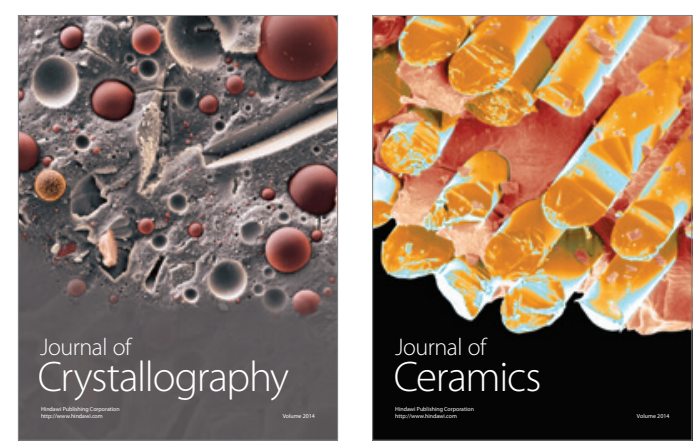
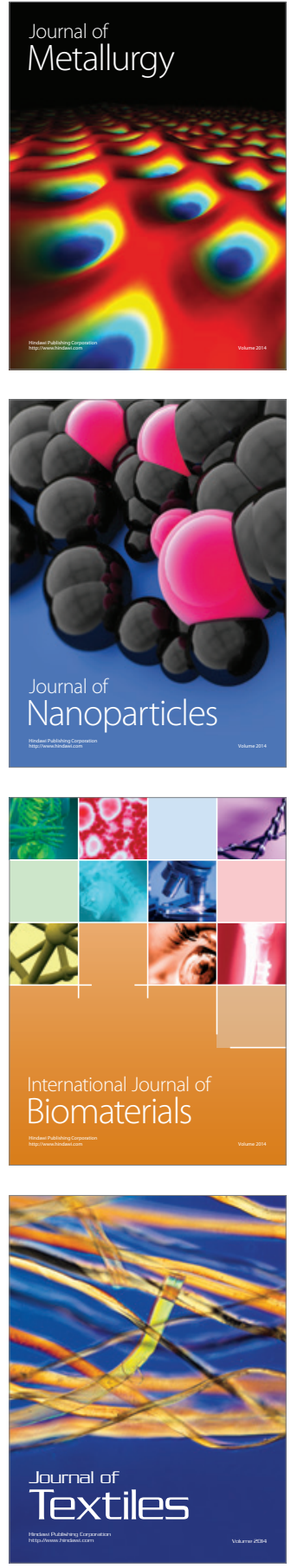